\title{
Laboreal
}

Volume $4 \mathrm{~N}^{\circ} 1$ | 2008

Ergologia, trabalho, desenvolvimentos

\section{O RH está nu : tramas e urdiduras por uma gestão coletiva do trabalho}

El RH está desnudo : tramas y urdiduras por una gestión colectiva del trabajo

Le RH est nu : trames et chaînes pour une gestion collective du travail

The HR is naked : trams and warps for a collective work management

\section{Maria Elisa Siqueira Borges}

\section{(2) OpenEdition}

Journals

Edição electrónica

URL: http://journals.openedition.org/laboreal/11968

DOI: $10.4000 /$ laboreal. 11968

ISSN: 1646-5237

\section{Editora}

Universidade do Porto

Refêrencia eletrónica

Maria Elisa Siqueira Borges, « O RH está nu : tramas e urdiduras por uma gestão coletiva do trabalho », Laboreal [Online], Volume $4 \mathrm{~N}^{0} 1$ | 2008, posto online no dia 01 julho 2008, consultado o 24 setembro 2020. URL : http://journals.openedition.org/laboreal/11968; DOI : https://doi.org/10.4000/ laboreal.11968

Este documento foi criado de forma automática no dia 24 setembro 2020.

Laboreal está licenciado com uma Licença Creative Commons - Atribuição-NãoComercial 4.0 Internacional. 


\title{
O RH está nu : tramas e urdiduras por uma gestão coletiva do trabalho
}

\author{
El RH está desnudo : tramas y urdiduras por una gestión colectiva del trabajo \\ Le RH est nu : trames et chaînes pour une gestion collective du travail \\ The HR is naked: trams and warps for a collective work management
}

Maria Elisa Siqueira Borges

\section{REFERÊNCIA}

Borges, M. E. (2006) O RH está nu : tramas e urdiduras por uma gestão coletiva do trabalho. Tese de Doutoramento. Programa de Pós-graduação em Psicologia Social da Universidade do Estado do Rio de Janeiro, Rio de Janeiro/Brasil.

\section{NOTA DO EDITOR}

Manuscrito recebido em : Abril/2008

Aceite após peritagem em : Junho/2008

\section{Introdução}

1 O principal objetivo da tese foi compreender/transformar a atividade dos profissionais de "Recursos Humanos" (ou "Gestão de Pessoas", ou Gestão do Trabalho, como preferimos). Utilizamos durante toda a tese uma metáfora construída a partir do conto de Hans Christian Andersen : A Roupa Nova do Rei. Trata-se da história de um rei que fora enganado por tecelões trapaceiros que prometeram vesti-lo com um traje belo e caríssimo que só poderia ser visto por pessoas inteligentes. Esta história aliada à metáfora utilizada por Daniellou (2004) para se referir ao trabalho (a trama e a urdidura) deram origem ao título e se tornou o fio condutor da tese. 
2 Em uma perspectiva ergológica, buscamos investigar no cotidiano do trabalho de profissionais de Gestão de Pessoas, que tipo de gestão esses profissionais fazem ? Que possibilidades de agir eles desenvolvem, tendo em vista as atuais exigências do capitalismo nos mundos do trabalho e as prescrições que daí advêm ? Na gestão que fazem do seu trabalho, de sua atividade, que (im)possibilidades estão aí contidas, no sentido de desenvolver uma gestão coletiva do trabalho, uma ergogestão ?

3 A própria denominação desse "campo" de atuação foi colocada em análise. Falar dos humanos como recursos ou afirmar a pretensão de gerir pessoas parece partir de um mesmo pressuposto: o de que as 'pessoas' - como os outros recursos - não são protagonistas ativos de sua vida e seu trabalho, são apenas agregadas enquanto força de trabalho na produção de valor de capital e se submetem a ele, como meros suportes de uma pura heterodeterminação. Remete à idéia de que as pessoas precisam ser administradas ou geridas para poder melhor realizar seu trabalho. Pior, crêem na possibilidade de que as pessoas sejam geríveis...

4 Defendeu-se a idéia de olhar para os coletivos de trabalho não nesta ótica, mas como protagonistas da atividade em foco, trabalhadores (individuais e coletivos) que já fazem seu trabalho gerindo-o coletivamente, em alguma medida. E querem desenvolver esta potência de vida. Na medida em que não se admite, reconhece, valoriza, avalia essa gestão que é praticada, cotidianamente, nos mundos do trabalho, uma abordagem que objetiva "administrar recursos" ou "gerir pessoas" torna-se um obstáculo éticoepistemológico ao desenvolvimento teórico-metodológico-técnico desse campo.

5 Destacou-se a fragilidade, em todos os planos, deste ' $\mathrm{RH}^{\prime}$ ou 'GP'. Por um lado, encontra-se em plena evidência diante da importância que ganhou a partir das transformações tecnológico-organizacionais contemporâneas. Por outro, em plena fragilidade por não apresentar uma reflexão e sistematização teórico-metodológica e de prática técnico-profissional de intervenção à altura da nobreza do que está em jogo. A reboque de "saberes" de consistência cientificamente duvidosa, o RH tem se deixado levar por valores "de momento", assumindo feições diferenciadas de acordo com as exigências conjunturais do capitalismo e da formação social brasileira (importadora de tecnologias, inclusive de gestão). Tudo parece caber nas práticas de $\mathrm{RH}$, desde as práticas mais sérias até às mais manipulatórias e/ou medíocres e mediocrizantes. Práticas que, muitas vezes, insistem em simplificar - mutilando - a complexidade da vida, dos humanos e do trabalho humano.

\section{Referenciais teóricos}

6 Utilizou-se como ponto de partida teórico a distinção apontada pela Ergonomia da Atividade entre "trabalho prescrito" e "trabalho real", a partir da qual a Ergologia faz uma rica elaboração, agregando contribuições no sentido de ampliá-la, transformá-la. Os conceitos de gestão de si (do corpo-si) e dramáticas do uso de si, assim como o paradigma ergológico, com seu dispositivo dinâmico de três pólos - DD3P (Schwartz

7 \& Durrive, 2007) foram essenciais para a compreensão do problema da tese e seu desenvolvimento, chamando a atenção para a complexidade do trabalho, seu caráter sempre enigmático, do ponto de vista transversal da atividade. Os materiais da Clínica da Atividade e da Lingüística Dialógica (envolvendo particularmente Yves Clot e Daniel Faïta, (Clot, Faïta, Fernandez \& Scheller, 2001) evidenciaram a importância da atividade 
linguageira para compreender o trabalhar e o papel que ela desempenha na própria construção da atividade de trabalho.

\section{Metodologia}

8 Tendo a Ergologia como orientação, trazendo em seu interior as experimentações do Modelo Operário Italiano de luta pela saúde - MOI (Oddone, Briante \& Re, 1981), mobilizamos ferramentas da Ergonomia da Atividade e de abordagens clínicas do trabalho, especialmente a Clínica da Atividade. Constituímos a modalidade de dispositivo dinâmico de três pólos que temos operado no Brasil, que denominamos Comunidade Ampliada de Pesquisa - CAP (Brito \& Athayde, 2003), onde circula uma comunidade dialógica. Com a participação dos profissionais de um setor do Banco do Brasil denominado 'Gestão de Pessoas' (Gepes) e profissionais de pesquisa em Psicologia do Trabalho e Lingüística Dialógica, utilizamos como dispositivo-chave os "Encontros sobre o Trabalho" da Comunidade Ampliada de Pesquisa. Estes encontros possibilitaram a criação de um espaço de diálogo-debate sobre a atividade, reunindo profissionais dos saberes disciplinares e os protagonistas da atividade em foco.

Entendemos que o dispositivo criado facilitou a expressão da atividade de trabalho desses profissionais, sua reflexão e desenvolvimento.

Foram realizados seis encontros com a participação de 20 profissionais (17 da Gepes e 3 pesquisadores). Os profissionais da Gepes variavam segundo a idade (menos de 30 a mais de 50 anos); formação (Psicologia, Pedagogia, Medicina, Direito, Economia, Ciências Contábeis, Administração, Fonoaudiologia) ; tempo de experiência em Gestão de Pessoas (menos de um ano a mais de dez anos). Dentre os pesquisadores, estavam a autora desta tese, uma auxiliar de pesquisa, doutoranda em Psicologia do Trabalho e uma doutora em Lingüística. Os encontros foram realizados na Gepes em horário normal de expediente de trabalho e o critério para participar do grupo foi a adesão voluntária.

\section{Análises}

11 A análise dos materiais produzidos apontou algumas "pistas" para as possibilidades do desenvolvimento de uma dada gestão coletiva do trabalho, uma ergogestão :

1. Os profissionais da Gepes se utilizaram de muitas e belas metáforas para falar de seu trabalho: o "curativo" para expressar o que fazem nas pessoas que os procuram; o "funil" ou o "gargalo" para representar a comunicação dentro da empresa; a "borracha" significando a forma como eles amortizam as "marteladas" que os "funcionários-pregos" recebem de seus gerentes. Através dessas metáforas eles expressaram as "dramáticas de uso de si" que põem em ação ao fazer a gestão de sua atividade, para além das contradições, precariedades e impedimentos. Os dispositivos utilizados facilitaram a expressão dessas metáforas, provocando-os ao movimento, inclusive discursivo. Isso possibilitou àquele coletivo de trabalho se distanciar da experiência vivida para transformá-la em meio para produzir outras experiências, desenvolvendo seu poder de agir, conforme proposta de Vigotski (1998), desenvolvida pela Clínica da Atividade. Através do uso de metáforas, o 'coletivo Gepes' revelou traços da competência que buscam operar para gerir coletivamente seu trabalho. Demonstraram que, apesar dos inevitáveis paradoxos do trabalho, dos impedimentos e suas próprias limitações no plano teórico-metodológico (pela ausência de 
um patrimônio mais rico), inventam meios para continuar trabalhando, evidenciando as tensões permanentes nas dramáticas de usos de si.

2. Eles identificaram que ter trabalhado anteriormente nas agências do Banco representa um patrimônio, um ingrediente da competência necessária para se realizar seu trabalho. Desta forma, ao defrontar-se com a realidade de seu trabalho, reivindicam o ponto de vista da atividade como ferramenta de trabalho. Neste sentido, o 'coletivo Gepes', em seu cotidiano de trabalho, não é passivo aos obstáculos que encontra, assumindo-os como desafios.

3. Reconheceram através de metáforas (especialmente a metáfora do curativo: em alguns momentos é apenas manipulação, em outros momentos surte o efeito desejado) que os recursos genéricos que utilizam para trabalhar apresentam uma dupla face 'funcionar/não funcionar', o que evidencia um gênero profissional frágil, fragmentado e cindido. Mas, no movimento do diálogo, ao re-elaborar coletivamente as metáforas, o coletivo Gepes aposta na positividade (no curativo que efetivamente cura), na possibilidade contida no lado Gepes que funciona, "apesar de tudo".

4. $O$ coletivo Gepes utilizou frequentemente verbos de movimento para se referir ao par ouvir/ escutar, trazendo para o debate na CAP uma escuta que envolve "estar perto para poder ouvir", "olhar para as pessoas", "chegar junto", “ir onde o Banco está". Desta forma, eles expressaram uma concepção nada passiva dessa escuta-ação, que envolve movimento, atividade ("ter sensibilidade", ter "postura ativa") ; uma escuta diretamente relacionada a um corpo-si que vai além do biológico, na verdade uma "entidade coletiva relativamente pertinente" (Schwartz, Y. \& Durrive, L., 2007), um corpo social, físico, institucional, atravessado por normas, valores, relações com o tempo, com os homens, etc.

5. Ao se utilizarem de um linguajar referente ao cuidado que é preciso ter com o outro na "Gestão de Pessoas" (“cuidar”, "acolher”, "dar colo", “amparar”) apontam para o fato de que frente às dificuldades que surgem em situações em que não há prescrições pertinentes, eles recorrem a um outro gênero, disponível para as mulheres, o gênero gestionário matriz: mãe/maternidade/família. O corpo-si tem aí um papel decisivo, uma racionalidade do pathos, da afecção, da paixão humana e eles expressam nas palavras e na lógica deste gênero, o "colo", o "carinho", o "acolhimento". Mas a motricidade do diálogo também evidenciou um tipo de racionalidade, que "analisa", que "avalia", que "julga", verbos que eles utilizaram diversas vezes, evidenciando o uso de um tipo de inteligência mais racional, que não somente a do corpo e da astúcia (Dejours, 1992). Uma gestão coletiva do trabalho não teria que operar colaborando para pôr essas inteligências em sinergia, em uma 'zona de desenvolvimento'?

6. Questionaram o sentido de que a GP seria o "lugar privilegiado" para gerir as dialéticas entre o pólo mercantil que visa o lucro e o pólo político relativo ao bem comum (Schwartz \& Durrive, 2007), não acreditando ser possível que um único setor da empresa possa ter o monopólio de gerir essa dialética ou possuir o monopólio de gestão das questões humanas na empresa - o que é absolutamente simplificador e mutilante.

\section{Considerações finais}

12 De uma maneira geral, podemos afirmar, a partir da pesquisa que conhecer, assumir e valorizar a dimensão gestionária que cada humano faz de seu trabalho (recentrando-o, fazendo-o seu), desenvolvendo essa gestão coletiva, implica em "olhar à lupa", o trabalho, interpelar seus processos, colocar problemas concretos e negociar coletivamente possíveis soluções, saindo, assim de falsos debates. E é isto que o coletivo Gepes reivindica, não apenas em um nível idealizado do trabalho (a "consciência ideal"), mas também no plano do realizado e do real da atividade. 
13 Em relação à atividade dos profissionais de $\mathrm{RH}$, esta tese oferece pistas na busca de ferramentas teórico-metodológicotécnicas que operem com o ponto de vista da atividade (normalmente ausente nas análises desses profissionais), no sentido do desenvolvimento de uma gestão coletiva do trabalho. Colocar este ponto de vista como centro dos debates sobre o trabalho pode fazer avançar algumas questões tão caras às empresas e aos "RH", em particular, como : desempenho, motivação, produtividade \& qualidade (de trabalho e de vida), saúde, confiabilidade e segurança.

\section{BIBLIOGRAFIA}

Brito, J. \& Athayde, M. (2003). Trabalho, educação e saúde : o ponto de vista enigmático da atividade. Trabalho, Educação e Saúde 1(2) : 239-265, 2003. http://www.revista.epsjv.fiocruz.br.

Clot, Y., Faïta, D., Fernandez, G. \& Scheller, L. (2001). Entretiens en Autoconfrontation Croisé : un méthode en clinique de l'activité. Education Permanente, 146, pp. 17-27.

Daniellou, F. (2004). A Ergonomia em Busca de seus Princípios. Debates epistemológicos. São Paulo : Ed. Edgard Blücher.

Dejours, C. (1992). A loucura do trabalho. São Paulo : Cortez/Oboré. Oddone, I., Briante, G. \& Re, A. (1981). Redécouvrir l’Expérience Ouvrière :

vers une autre psychologie du travail ? Paris : Ed. Sociales.

Schwartz, Y. \& Durrive, L. (org.) (2007). Trabalho \& Ergologia : conversas sobre a atividade humana. Niterói : Editora da Universidade Federal Fluminense.

Vygotski, L. S. (1998). A formação social da mente : o desenvolvimento dos processos psicológicos superiores. Michael Cole et all. (Ogs.). São Paulo : Martins Fontes.

\section{AUTOR}

\section{MARIA ELISA SIQUEIRA BORGES}

Diálogos - Consultoria em Gestão com Pessoas ; Grupo de Pesquisa Actividade CNpq, Rua Peri 299 ap.103 - CEP 224-100 - Rio de Janeiro RJ Brasil melisaborges@uol.com.br 